\title{
ELABORAÇÃO E ACEITABILIDADE PÃO ENRIQUECIDO COM FARINHA DE LINHAÇA E CENOURA.
}

\author{
L. de O. $\operatorname{COSTA}^{1}$, G. de BARBOSA ${ }^{1}$, N. M. do A. FERREIRA ${ }^{1}$, L.B. V. TORRES ${ }^{2}$
}

\begin{abstract}
1. Graduanda pela Universidade Federal do Ceará, Departamento de Tecnologia de Alimentos. laiana.costa@hotmail.com

2. Professora Dra. na Universidade Federal do Ceará, Departamento de Tecnologia de Alimentos. lucicleiabarros@hotmail.com
\end{abstract}

\begin{abstract}
RESUMO - Com a finalidade de atender as expectativas do consumidor em relação a um alimento com alto teor de fibras foi elaborado um pão de cenoura enriquecido com linhaça. Esse alimento apresenta grande apelo visual, devido a sua coloração alaranjada, que pode despertar o estimulo do público infantil pelo consumo de alimentos coloridos, saudáveis e ricos em fibras. Foram desenvolvidas duas formulações variando apenas a porcentagem de linhaça (formulação "A" $15 \%$ e a formulação "B" 10\%). A análise sensorial foi realizada no Laboratório de Cereais da UFC e baseou-se no teste de aceitação das formulações. Foi observado que o aroma e a impressão global foram os atributos sensoriais que mais influenciaram os provadores com relação ao grau de aceitação de ambas as amostras. Por outro lado, o sabor e a cor alternaram-se como a terceira causa mais influente relacionada ao grau de aceitação. Em relação a textura a amostra B decresceu um pouco em relação a amostra $\mathrm{A}$, devido ao baixo teor de linhaça.
\end{abstract}

\section{INTRODUÇÃOO}

Por definição, pão é o produto obtido pela cocção, em condições tecnologicamente adequadas, de uma massa, fermentada ou não, preparada com farinha de trigo e/ou outras farinhas que contenham naturalmente proteínas formadoras de glúten ou adicionadas das mesmas e água, podendo conter outros ingredientes. Já o pão integral é definido como produto preparado, obrigatoriamente, com farinha de trigo e farinha de trigo integral e/ou fibra de trigo e/ou farelo de trigo, sendo que o percentual da farinha de trigo integral deve ser maior do que o da farinha branca (BRASIL, 2000).

A popularidade do pão é devida, sem dúvida, ao sabor agradável, preço e fácil disponibilidade em milhares de padarias e supermercados do País. O segmento de panificação e 
confeitaria no Brasil representa um faturamento anual ao redor de US\$ 16 bilhões. A mão-de-obra direta empregada pelo setor é de 550.000 pessoas (BRASIL, 2002/2003).

Segundo Bortholazi (2005) é importante a inclusão de fibras na alimentação diária, pois fornecem flexibilidade aos resíduos alimentares, reduzem o tempo de trânsito intestinal e previnem inúmeras doenças como câncer de cólon, doença diverticular, hemorroidas e constipação sendo úteis também no controle de peso, apresentando um efeito de saciedade maior do que os produtos refinados.

A incorporação da cenoura na alimentação diária é ideal por ser um alimento indispensável para crianças em fase de desenvolvimento e também para os adultos, pois além de ser rico em fibras, carrega grande quantidade de vitamina A. Além das vitaminas B e C, que beneficiam o sistema nervoso e estimulam as defesas orgânicas contra enfermidades. Outro alimento indispensável a alimentação é a semente de linhaça que hoje é considerada um alimento funcional, depois de séculos de uso na alimentação e na medicina natural. Os benefícios da linhaça são atribuídos ao seu óleo rico em ácido alfa linolênico, ao alto teor de lignanas e às fibras alimentares (Lee et al., 1991).

Segundo Mauricio (2012) a crescente exigência do consumidor por alimentos de qualidade sensorial, nutricional e que tragam benefícios à saúde, fazem surgir à necessidade de novos produtos que atendam essa demanda. A análise sensorial é utilizada como instrumento para a avaliação da qualidade sensorial dos alimentos medindo e analisando as reações em relação às características dos mesmos, que possam ser diferenciadas pela avaliação humana (DUTCOSKY, 1996).

Diante do exposto este trabalho teve como objetivo a elaboração de um pão, que possa atender as expectativas do consumidor em relação a um alimento com alto teor de fibras e que tenha forte apelo visual de coloração alaranjada, estimulando o consumo infantil por alimentos saudáveis e ricos em fibra.

\section{MATERIAL E MÉTODOS}

\subsection{ELABORAÇÃO DO PÃO DE CENOURA ENRIQUECIDO COM FARINHA DE LINHAÇA.}

De acordo com a Tabela 1, na elaboração do pão de cenoura duas formulações foram desenvolvidas, com variação na quantidade de linhaça, estando presentes 15 e $10 \%$ de linhaça para as formulações A e B, respectivamente. 


\begin{tabular}{lll}
\hline Componentes & Formulação "A" & Formulação "B" \\
\hline Farinha de Trigo & $100 \%$ & $100 \%$ \\
Cenoura Cozida & $51 \%$ & $51 \%$ \\
Leite & $48 \%$ & $48 \%$ \\
Açúcar & $32 \%$ & $32 \%$ \\
Oleo & $24 \%$ & $24 \%$ \\
Ovos & $15,4 \%$ & $15,4 \%$ \\
Farinha de Linhaça & $15 \%$ & $10 \%$ \\
Fermento Biológico & $6 \%$ & $6 \%$ \\
Margarina & $4 \%$ & $4 \%$ \\
Sal & $0,8 \%$ & $0,8 \%$ \\
\hline
\end{tabular}

Tabela 1. Formulação do pão de cenoura enriquecido com farinha de linhaça.

Inicialmente todos os ingredientes foram pesados. O processamento (Figura 1) foi iniciado com a homogeneização de todos os ingredientes secos: farinha de trigo, farinha de linhaça, fermento biológico, açúcar e sal. Antes de unir os ingredientes secos aos úmidos, descascou-se a cenoura e foi realizado seu cozimento em água fervente. A massa foi obtida, acrescentando aos ingredientes secos os ingredientes úmidos (os ovos, a margarina, o óleo, a cenoura cozida e o leite) que haviam sido previamente batidos em um liquidificador; sovou-se a massa, e deixou-a em descanso por 1 hora em temperatura ambiente $\left(\approx 27^{\circ} \mathrm{C}\right)$ até que a fermentação ocorresse, ou seja, até que o volume da massa dobrasse de tamanho. Após esta etapa, a massa foi sovada, moldada e deixada em descanso novamente por 30 minutos para que ocorresse a $2^{a}$ fermentação, que tem por função distribuir os levedos desenvolvidos e espalhá-los. Na sequência a massa foi colocada nas fôrmas previamente untadas com óleo e levada ao forno pré-aquecido a $200^{\circ} \mathrm{C}$ por cerca de 30 minutos. 


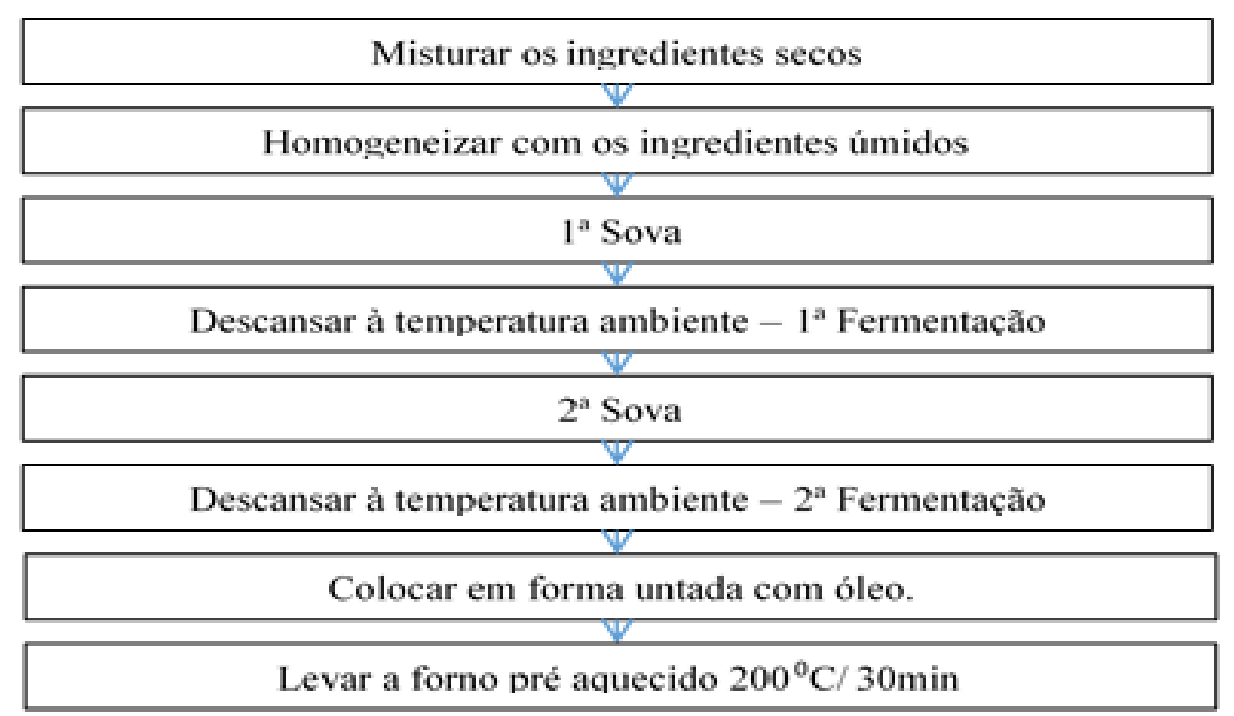

Figura 1 - Fluxograma do processo de produção do pão enriquecido com farinha de linhaça cenoura.

\subsection{ANÁLISE SENSORIAL}

A Análise Sensorial tem como objetivo constituir respostas subjetivas e reações espontâneas, por se tratar de provadores sem treinamento prévio, resultando em determinar a aceitabilidade ou preferência referente ao produto (ALMEIDA, 1999).

O teste foi realizado no Laboratório de Cereais da Universidade Federal do Ceará por 39 provadores não treinados (Figura 2) com duas amostras (A e B), entre as quais diferiu a concentração de farinha de linhaça. As amostras foram servidas de forma monádica (Figura 3) em copos descartáveis da cor branca e codificados. Empregou-se teste de aceitação utilizando-se uma escala de atitude de nove pontos, na qual o nove representava a nota máxima, "Gostei Muitíssimo", e um representava a nota mínima, "Desgostei Muitíssimo". Foram analisados os atributos: cor, aroma, sabor, textura e impressão global. (DUTCOSKY, 1996). 


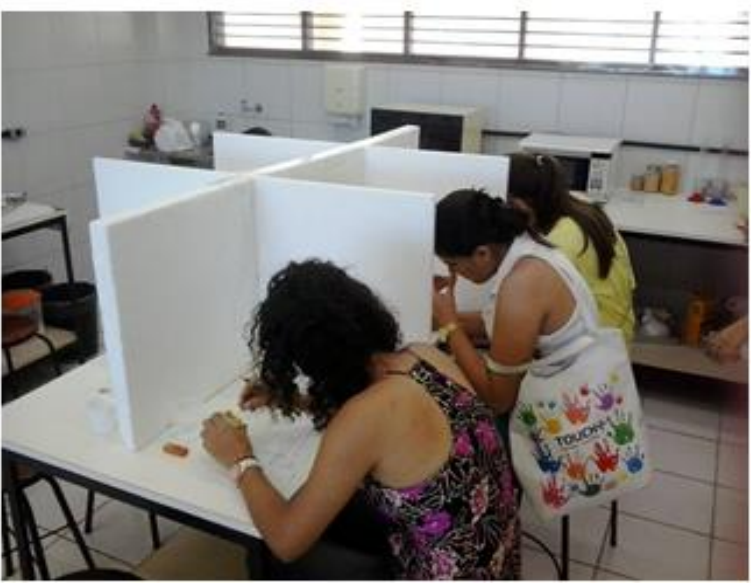

Figura 2 - Análise sensorial, realizada no Laboratório de Cereais da Universidade Federal do Ceará, por provadores não treinados.

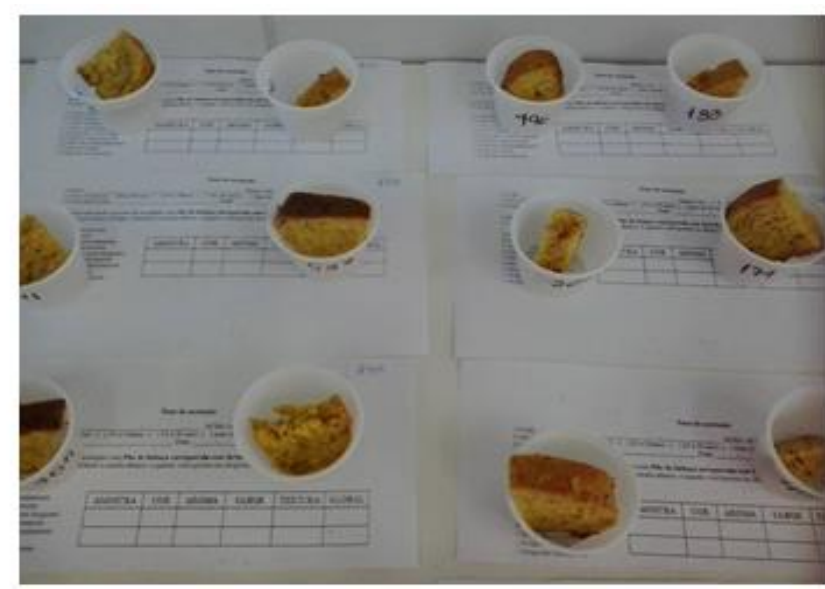

Figura 3 - Amostras A e B dispostas de forma monádica sobre as fichas utilizadas para o teste de aceitação.

\section{RESULTADOS E DISCUSSÃO}

As respostas dos provadores para o teste de aceitação do pão enriquecido apresentaram uma média de aceitação de 8,3 para amostra A (15\% de linhaça) e 8,25 para amostra B (10\% de linhaça) que corresponde à faixa compreendida entre as notas "Gostei Ligeiramente" e "Gostei Muitíssimo", significando que independente da concentração de linhaça presente o produto foi obtido um bom nível de aceitação dos consumidores, não apresentando grande diferença entre as amostras.

As médias obtidas para o atributo cor correspondem a 8,75 para amostra A e 7,25 para amostra B (Gráfico 1). Para o atributo aroma a amostra A apresentou média de 7,5 e a amostra B de 8,5(Gráfico 2). Em relação a textura (Gráfico 3), a amostra B obteve média maior, 7,75, enquanto a amostra A obteve 7,5, esse fato pode estar relacionado com a menor quantidade de linhaça na formulação que proporciona uma textura considerada mais agradável ao consumidor. As duas amostras apresentaram as mesmas médias para o atributo sabor (Gráfico 4), com 8,75, e impressão global (Gráfico 5), com 9. Esses resultados indicam que, para o consumidor, as duas amostras atingiram as mesmas características finais, com resultados positivos.

Considerando que ao se desenvolver um produto, um dos pontos principais é a avaliação de sua aceitabilidade junto aos consumidores, a fim de prever sua aprovação no mercado, à formulação do pão de cenoura enriquecido com farinha de linhaça se mostrou satisfatória. 


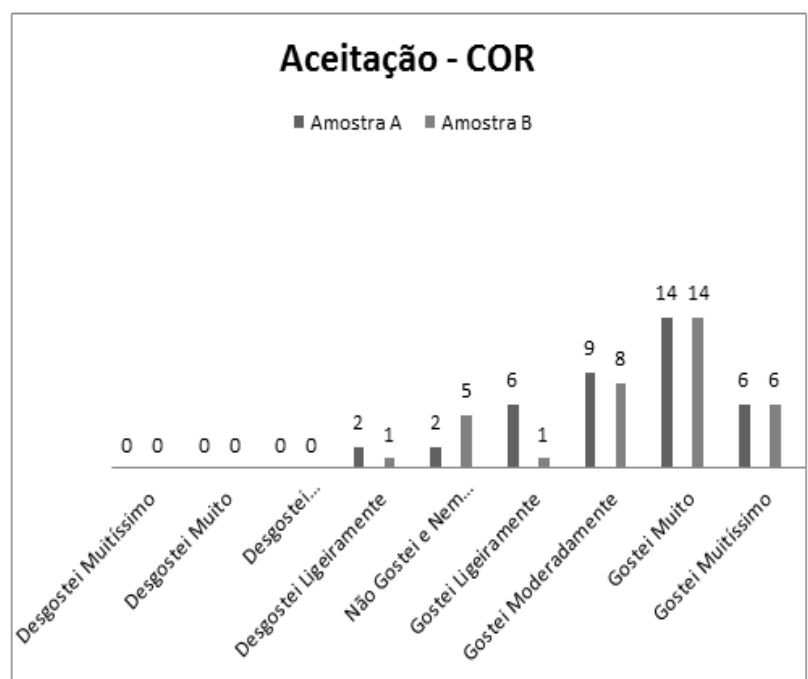

Gráfico 1 - Aceitação em relação a cor do pão enriquecido com farinha de linhaça e cenoura.

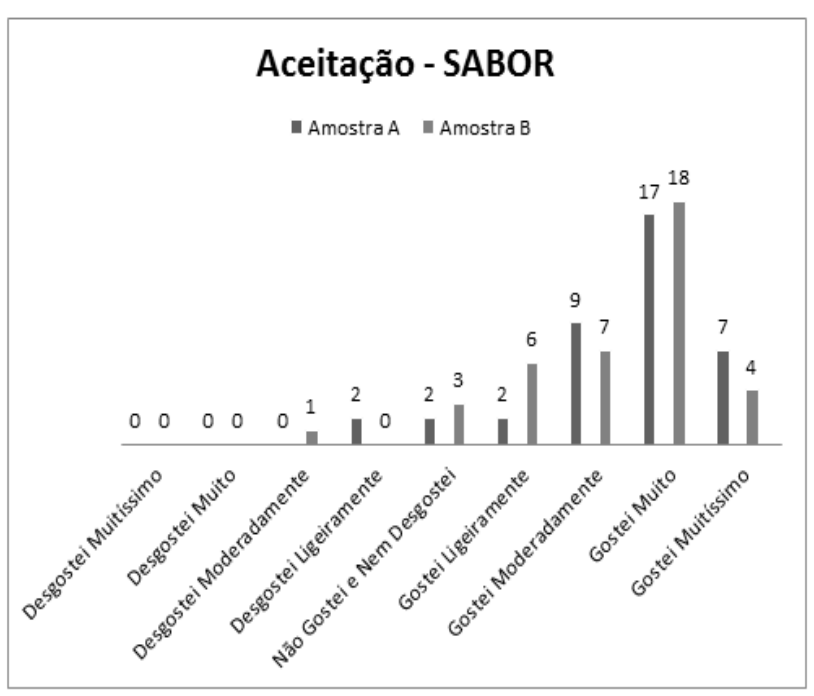

Gráfico 3 - Aceitação em relação ao sabor do pão enriquecido com farinha de linhaça e cenoura.

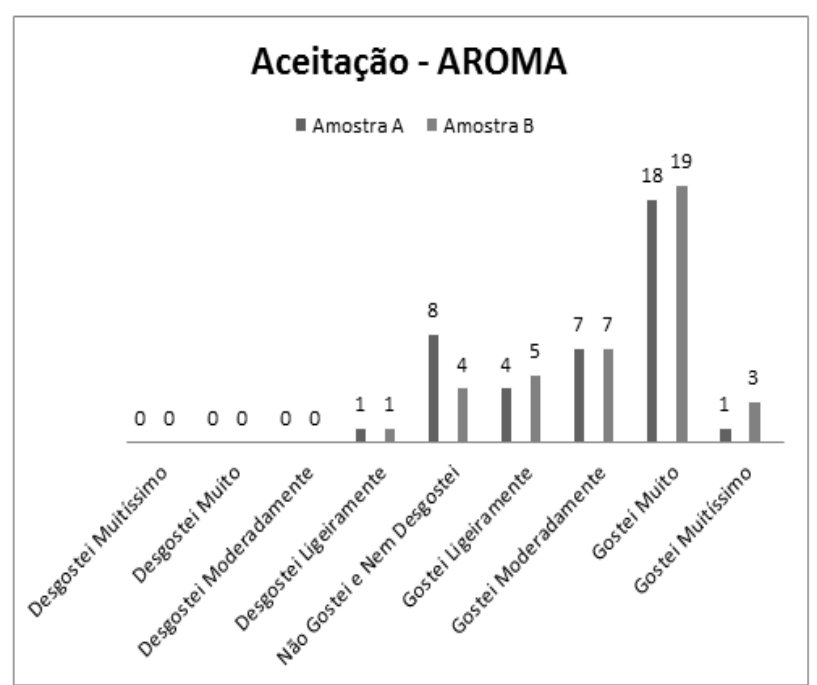

Gráfico 2 - Aceitação em relação ao aroma do pão enriquecido com farinha de linhaça e cenoura.

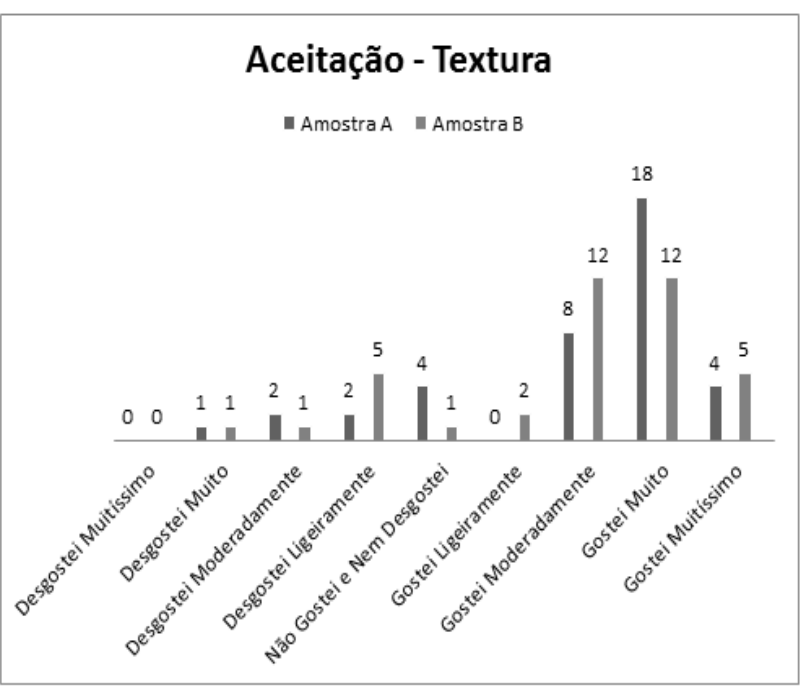

Gráfico 4 - Aceitação em relação a textura do pão enriquecido com farinha de linhaça e cenoura. 


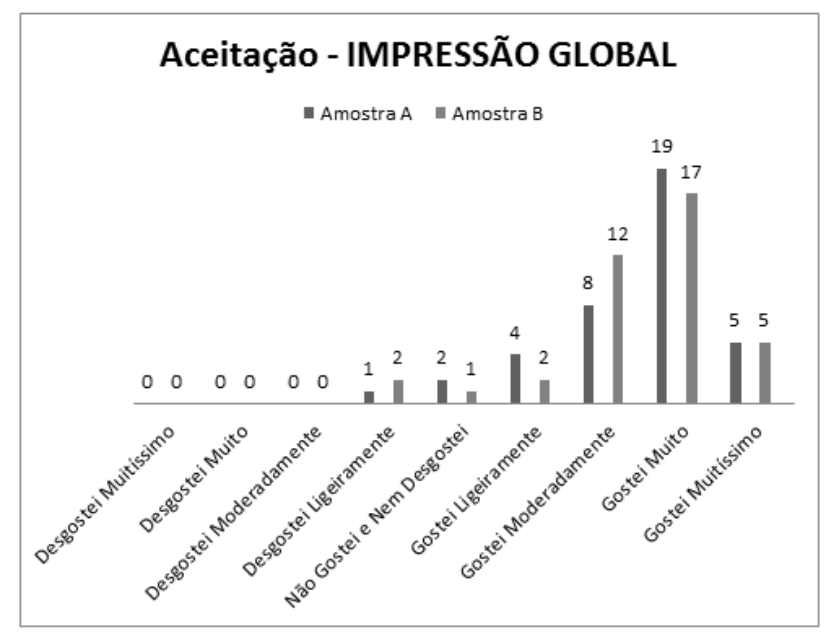

Gráfico 5 - Aceitação em relação a impressão global do pão enriquecido com farinha de linhaça e cenoura.

\section{CONCLUSÃO}

A elaboração do pão de cenoura enriquecido com farinha de linhaça atendeu as expectativas propostas neste estudo ao formular um alimento visualmente atrativo, pela sua coloração alaranjada e rico em fibras, devido a presença da cenoura e a incorporação da linhaça. O produto obteve resultados satisfatórios em relação a todos os atributos analisados independente da concentração de linhaça presente no produto, não sendo observada diferença expressiva entre as amostras, demonstrando a alta aceitabilidade do pão pelos consumidores.

\section{REFERENCIAS}

ALMEIDA, T.C.A; Hough, G.; Damásio,M.H.; da SILVA, M.A.A.P. avanços em análise sensorial - São Paulo -1999 - livraria Varela pag.13.

BRASIl. Portaria RDC $\mathrm{n}^{\circ}$ 90, de 18 de outubro de 2000. Aprova regulamento técnico para fixação de identidade e qualidade do pão. Agência Nacional de Vigilância Sanitária. Disponível em: http://www.anvisa.gov.br/alimentos/legis/especifica/regutec.htm. Acesso em: 20 abri. 2014.

BRASIL. Associação brasileira das indústrias de panificação e confeitaria. Análise do mercado de pães, 2002/2003. Disponível em: http://www.abip.org.br. Acesso em: $1^{\mathrm{o}}$ jun. 2005.

BORTHOLAZZI, K. D.; LUPPI, L. O.; BELLARDE, F. B. Elaboração de um macarrão enriquecido com fibras. Nutrire, vol.30, n.Suplemento, p.340-340, 2005.

DUTCOSKY, Silvia Deboni. Análise sensorial de alimentos. Curitiba: Champagnat, 1996. 
Lee, H.P.; Gourley, L.; Duffy, S.W.; Estéve, J.; Lee, J.; Day, N.E. Dietary effects on breast cancer risk in Singapore. The Lancet. v.337, p.1197-1200, 1991.

MAURÍCIO, A. A.; BUCHARLES, P. B; BOLINI, H. M. A.; SOUSA, V. M. C. Bolo de cenoura com e sem glúten: desenvolvimento da formulação e aceitação do produto. Revista Agro@mbiente On-line, v. 6, n. 3, p. 250-257, setembro-dezembro, 2012. 